\title{
Isolation and characterization of differentially expressed transcripts from the suspension cells of oil palm (Elaeis guineensis Jacq.) in response to different concentration of auxins
}

\begin{abstract}
Oil palm suspension cultures were initiated by transferring the gel-like friable embryogenic tissue onto liquid medium supplemented with auxins. In this study, transcripts that were differentially expressed in oil palm suspension cells cultured at different auxin concentrations were examined using suppression subtractive hybridization. Total RNA was first isolated from oil palm suspension cells proliferated in liquid medium with different hormone concentrations for 6 months. Four different hormone combinations: T1 (0.1 mg/l 2,4-D and $1.0 \mathrm{mg} / \mathrm{l} \mathrm{NAA}), \mathrm{T} 2$ (0.4 mg/l 2,4-D and $1.0 \mathrm{mg} / \mathrm{l} \mathrm{NAA}), \mathrm{T} 3$ (1.0 mg/l NAA), and T4 (0.4 $\mathrm{mg} / \mathrm{l}$ 2,4-D) were used for the treatments. The first and second subtractions were performed using samples $\mathrm{T} 1$ and $\mathrm{T} 2$ in forward and reverse order. The other two subtractions were forward and reverse subtractions of $\mathrm{T} 3$ and $\mathrm{T} 4$, respectively. Reverse northern analyses showed that $14.13 \%$ of these clones were preferentially expressed in $\mathrm{T} 1,13.70 \%$ in $\mathrm{T} 2$, $14.75 \%$ in T3, and $15.70 \%$ in T4. Among the 294 cDNA clones that were sequenced, 61 contigs (assembled from 165 sequences) and 129 singletons were obtained. Among the 61 contigs, 10 contigs consist of sequences from treatment T1, 8 contigs were from treatment $\mathrm{T} 2,10$ contigs were contains sequences of treatment T3 and 13 contigs contains sequences of treatment T4. Northern analyses of five transcripts that were shown to be differentially expressed in the oil palm suspension cells by reverse northern analysis revealed that transcripts 16A1 (a putative lignostilbene-Ŭ,6-dioxygenase, EgLSD) and 16H12 (a putative ethylene responsive 6, EgER6) were differentially expressed in oil palm suspension cells treated with different levels of auxin.
\end{abstract}

Keyword: EgLSD; EgER6; Oil palm; Cell suspension; Somatic embryo; 2,4-D; NAA 